\title{
Thyrostroma carpophilum causing apricot shot-hole in Mexico
}

\author{
J. M. Tovar-Pedraza • V. Ayala-Escobar • O. L. Segura-León
}

Received: 11 May 2012 / Accepted: 7 January 2013 /Published online: 31 January 2013

(C) Australasian Plant Pathology Society Inc. 2013

\begin{abstract}
During the spring of 2010, two fungal isolates were obtained from apricot tissues with symptoms of shot-hole in the State of Mexico, Mexico. Based on morphology, cultural features, rDNA ITS sequence and the fulfilment of Koch's postulates on apricot leaves and fruits, the causal agent was identified as Thyrostroma carpophilum. This is the first report of $T$. carpophilum causing apricot shot-hole in Mexico.
\end{abstract}

Keywords Prunus armeniaca - Thyrostroma carpophilum . Pathogenicity $\cdot$ Fungal plant pathogen

Shot-hole disease of stone fruit trees, caused by the anamorphic fungus Thyrostroma carpophilum (=Wilsonomyces carpophilus, Stigmina carpophila) is a serious disease affecting the Prunus species in many regions of the world, particularly peaches and apricots (Adaskaveg et al. 1990; Ogawa et al. 1995; Ahmadpour et al. 2009). In Mexico, stone fruit trees (apricot, peach, plum, almond and sweet cherry) are cultivated for commercial production covering a total area of more than 60,000 ha (SIAP 2012).

During the spring of 2010, severe symptoms of shot-hole disease were observed on 75 to $80 \%$ of apricot trees (Prunus armeniaca) located in an orchard in the State of Mexico, Mexico. Disease symptoms were observed on leaves, twigs and fruits. On the leaves, symptoms included small circular purple lesions with pale centres, which gradually enlarged

J. M. Tovar-Pedraza $(\bowtie) \cdot$ V. Ayala-Escobar

Departamento de Fitopatología, Instituto de Fitosanidad,

Campus Montecillo, Colegio de Postgraduados, CP 56230,

Texcoco, Estado de México, Mexico

e-mail: jmtovar@colpos.mx

O. L. Segura-León

Departamento de Entomología y Acarología, Instituto de Fitosanidad, Campus Montecillo, Colegio de Postgraduados, CP 56230, Texcoco, Estado de México, Mexico and became necrotic in the centre until the centre fell out, giving the appearance of shot-hole (Fig. 1a-b). On the twigs, symptoms included small necrotic spots that become gradually larger and sunken. Finally, on the fruits, the pathogen caused sunken necrotic lesions with purplish halos (Fig. 1c-d). In seriously infected apricot trees, severe defoliation and the drop of young fruits was also observed.

Fungal isolations were made from five symptomatic leaves and five fruits, which were cut and surface sterilised by immersion in a $1 \%$ sodium hypochlorite solution, washed in sterile distilled water and placed on potato dextrose agar (PDA) at $18{ }^{\circ} \mathrm{C}$ under continuous white light. Fungal colonies were sub-cultured onto PDA and then single-spored to obtain pure cultures. Colonies observed after 6 days were effuse, grey to black in colour, with diffuse margins and abundant conidia. Conidiophores were cylindrical and golden brown, with up to 5 annellations. Conidia were straight, cylindrical to ellipsoidal, 20-55 $\times 6-15 \mu \mathrm{m}$, transversal septate $(3-5)$, rounded at the apex, truncated at the base, smooth, pale brown and had end-cells that were paler than the rest (Fig. 1e-f). All these characteristics were consistent with the description of Thyrostroma carpophilum (Sutton 1997).

Pathogenicity tests were conducted on three 10-monthold apricot plants by spraying a conidial suspension $(1.2 \times$ $10^{4}$ spores $/ \mathrm{mL}$ ) of a $T$. carpophilum isolate on leaves. An isolate of $T$. carpophilum was also used to inoculate three fruits. Three plants and fruits were mock inoculated with distilled water as a control. Plants were covered with plastic bags for $36 \mathrm{~h}$ to maintain high humidity and then they were placed on a greenhouse bench at $22 \pm 2{ }^{\circ} \mathrm{C}$. Fruits were placed in a moist chamber and maintained at $10{ }^{\circ} \mathrm{C}$. All inoculated leaves developed circular purple lesions with pale centres and fruits developed sunken necrotic lesions within 7 to 9 days after inoculation (Fig. $1 \mathrm{~g}-\mathrm{h}$ ), whereas mock inoculated plants and fruits remained disease-free. 

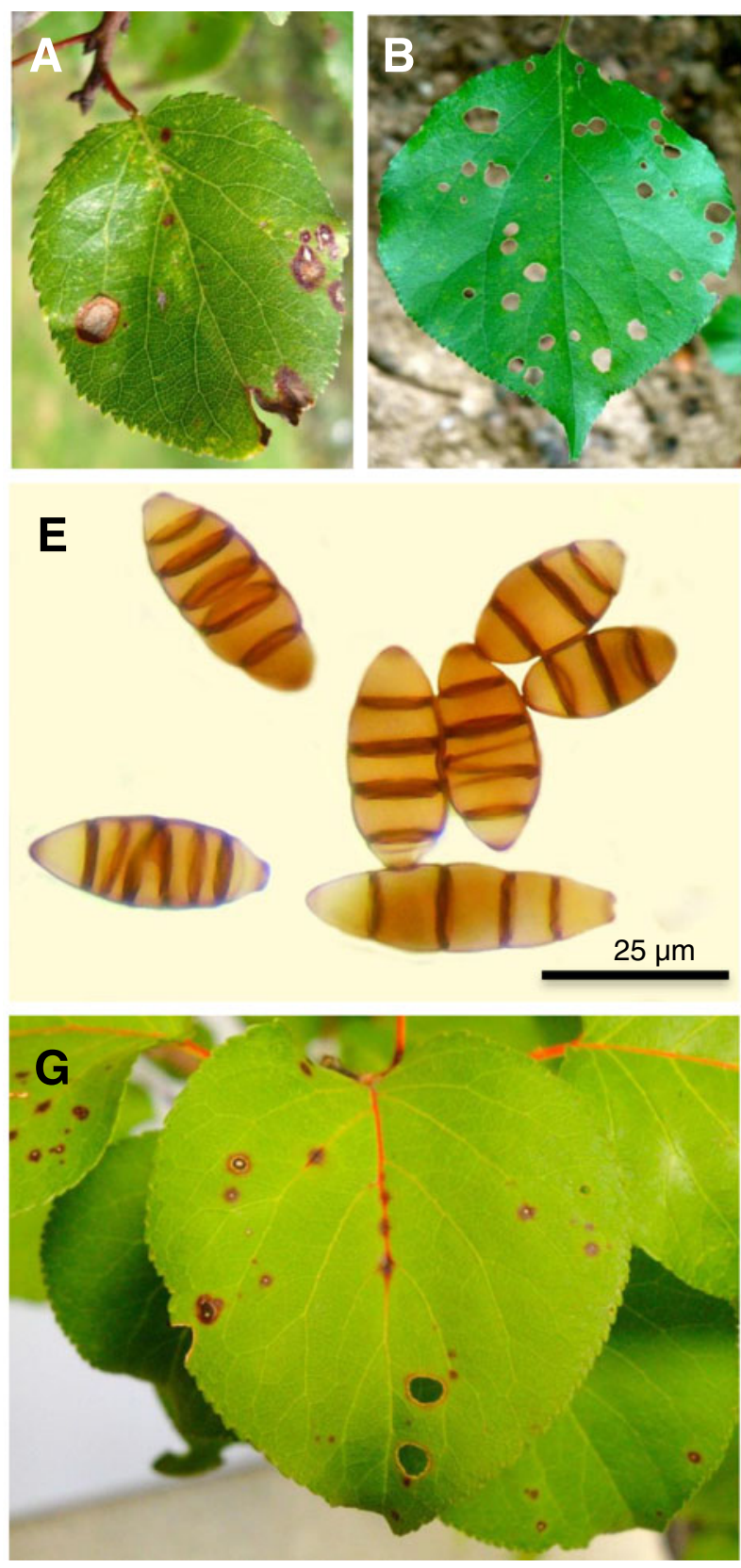
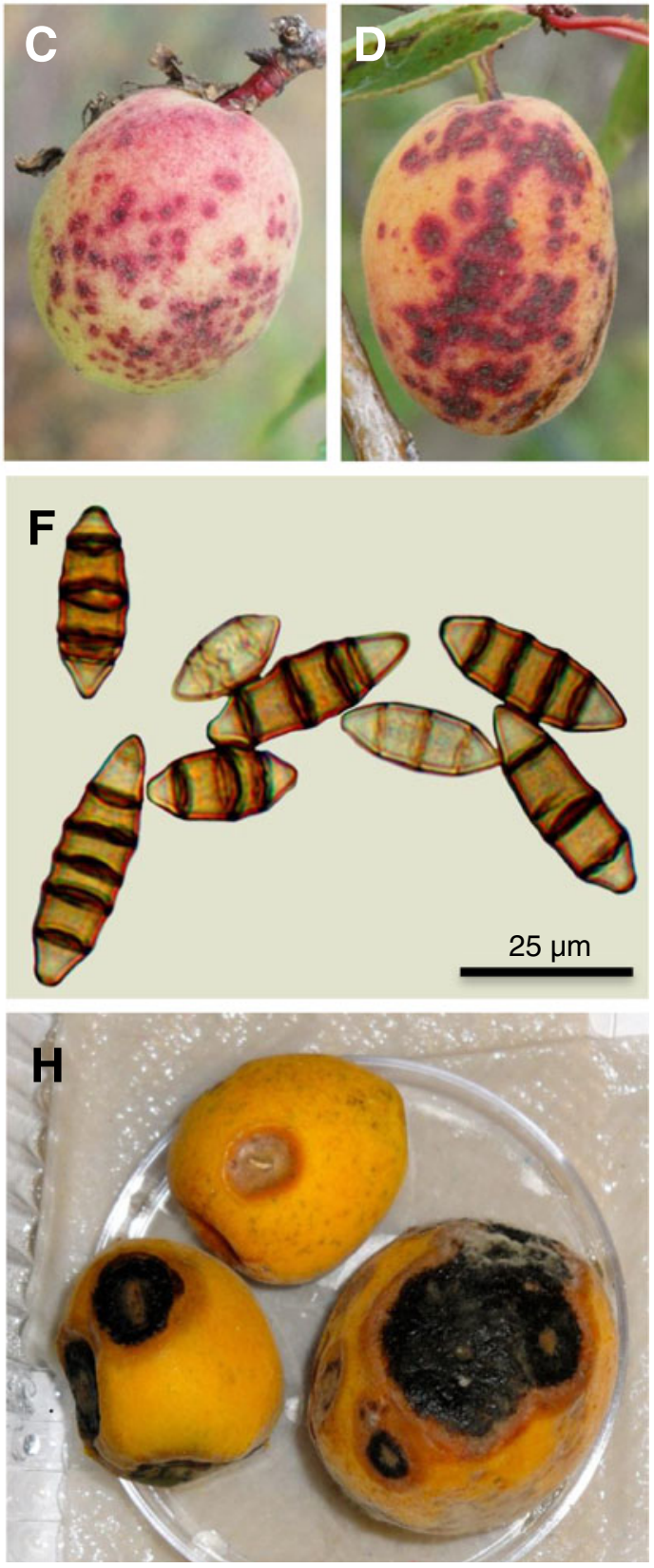

Fig. 1 a-b Shot-hole symptoms on leaves. c-d Shot-hole symptoms on fruits. e-f Conidia of Thyrostroma carpophilum. $\mathbf{g}-\mathbf{h}$ Shot-hole symptoms development during pathogenicity tests

The fungus was re-isolated from all of the inoculated plant tissues and was found to be morphologically identical to the original isolate sprayed on leaves and fruits, thus fulfilling Koch's Postulates. The experiment was repeated twice.

To confirm the identity of the fungus, genomic DNA was extracted from the mycelia of two isolates using a DNeasy Plant Mini Kit (Qiagen Inc, CA, USA) according to the manufacturer protocol. The rDNA internal transcribed spacer region (ITS1-5.8S- ITS2) of the two isolates was amplified using universal primers ITS1 and ITS4 (White et al. 1990) and sequenced using an AB 3730xl DNA Analyser (Applied
Biosystems, CA, USA). BLAST searches of two ITS sequences (GenBank Accession Nos. JN208891 and JN208892) had $99 \%$ identity with two isolates of T. carpophilum (GenBank Accession Nos. HM107422 and HM107423). The two cultures used in this study were deposited in the culture collection of herbarium "CMPH" of the Colegio de Postgraduados, Campus Montecillo, Orientación Fitopatología, Montecillo, Texcoco, State of Mexico, Mexico under the accession nos. HT005 and HT006. To the best of our knowledge, this is the first report of Thyrostroma carpophilum causing shoot-hole on apricot trees in Mexico. 


\section{References}

Adaskaveg JE, Ogawa JM, Butler EE (1990) Morphology and ontogeny of conidia in Wilsonomyces carpophilus, gen. nov., and comb. nov., causal pathogen of shot hole disease of Prunus species. Mycotaxon 37:275-290

Ahmadpour A, Ghosta Y, Javan-Nikkhah M, Fatahi R, Ghazanfari K (2009) Isolation and pathogenicity tests of Iranian cultures of the shot hole pathogen of Prunus species, Wilsonomyces carpophilus. Australas Plant Dis Notes 4:133-134. doi:10.1071/DN09054
Ogawa JM, Zehr EI, Bird GW, Ritchie DF, Uriu K, Uyemoto JK (1995) Compendium of stone fruit diseases. The American Phytopathological Society Press, St Paul

SIAP (2012) http://www.siap.sagarpa.gob.mx. Accessed: 1 April 2012 Sutton BC (1997) On Stigmina, Wilsonomyces and Thyrostroma (Hyphomycetes). Arnoldia 14:33-35

White TJ, Bruns T, Lee S, Taylor J (1990) Amplification and direct sequencing of fungal ribosomal RNA genes for phylogenetics. In: Innis MA, Gelfand DH, Sninsky JJ, White TJ (eds) In 'PCR protocols: A guide to methods and applications'. Academic, San Diego, pp 315-322 